JULIET SPRAKE and PETER ROGERS

\title{
Crowds, Citizens and Sensors: process and practice for mobilising learning
}

\author{
Goldsmiths, University of London
}

Lewisham Way

London SE14 6NW

$U K$

j.sprake@gold.ac.uk

07949095587

\begin{abstract}
Participatory sensing is an emerging field in which citizens are empowered by technologies to monitor their own environments. Harvesting and analysing data gathered in response to personal or local enquiries can be seen as an antidote to information provided by official sources. Democratising sensing means that ordinary people can learn about and understand the world around them better and can be a part of the decision making in improving environments for all. In this paper we review and describe participatory sensing and discuss this in relation to making a series of prototype tools and applications for mobile users - Located Lexicon, Where's Fenton? and Tall Buildings. In the first of these projects, Located Lexicon, we wanted to find out if a lexicon of terms derived from user generated content (UGC) could enable the formation of Twitter-like groups that allow users to engage in finding out more about their location. In the second project, Where's Fenton? we made a publicly available app that involves users in counting the abundance and logging the location of deer in a park. This project focused specifically on anonymity of the user in collecting data for a specific enquiry. In the last project, Tall Buildings, we experimented with using dimensions of altitude, distance and speed to encourage users to physically explore a city from its rooftops.
\end{abstract}

In all of these projects we experiment with the pedestrian as a human sensor and the methods and roles they may engage in to make new discoveries. The underlying premise for our work is that it is not possible to calibrate people to be identical so experimenting with crowd-sourced data opens up thinking about the way we observe and learn about the physical environment.

Keywords: crowd sourcing, citizen, location-based learning, participatory sensing 


\section{Participatory sensing and mobilised learning}

Researchers in GIS and healthcare have long recognised the potential for mass participation in using GIS and maps. Working within the health GIS community, Kamel Boulos has explored the potential of emerging geoinformatic services from Google and Microsoft in the production of online interactive health maps by nonexperts in programming. [1] And in Deptford Creek in 2005 we were sort of doing just that. Playing around with PDAs and Bluetooth devices in the mud of a tributary of the Thames in SE London, we tried to work out how young people might experience a heightened awareness of their surroundings. The big idea behind this project, Mudlarking in Deptford, was for young mobile learners to be able to produce an interactive map and tour of the area that other participants could add to and evolve over time. [2] With the help of Futurelab and Mobile Bristol HP Labs and their prototype application, mScape, we were able to 'attach' images, sounds and text to the physical environment via interactive zones on a digital map that were triggered by participants walking into or out of those zones with a GPS-enabled mobile toolkit. Albeit working at different scales and priorities in 2005, projects such as this highlighted emerging possibilities for non-experts to map and share local knowledge, stories and information in ways that invited further personal development of that content. We use the term 'user evolvement' to describe what we mean by participant production of guided walks using mobile devices. From a user's perspective the design of these kinds of experience shifts in emphasis from the management of one-directional information flow to consider how, where and when information can be discovered, shared and changed by participants.

Content that is designed to grow and evolve in different spaces and over time may be described as 'seeded'. Using the metaphor of 'seeded content' provides opportunities for thinking about what kind of data or information grows well, how environmental conditions interact with the content to affect growth and the spatial and temporal dispersal of content over a geographical location. Making connections in response to seeded content that involves mobile participants initiating and making threads of enquiry can be described as 'threading'. Another metaphor is used here to describe a horizontal mode of learning that involves participants in making imaginative associations and physical connections through interactions with seeded content and with each other whilst on-the-move. These two concepts together define what it means to be a productive participant in learning-through-touring. [3]

Drawing on perception theory and Paul Rodaway's work on Haptic Geographies, [4] we have since gone on to explore haptic learning as a process in which people are simultaneously physical, cognitive and emotional participants in developing a heightened sense of awareness. Specifically, they are reciprocally 'in touch with' and 'touched by' their physical environment as they move through it. Working through this theoretical concept in practice, we have explored how the environment can be enabled for learning to happen particularly in the use of cues that can be designed to instigate movement and connections between places.

Haptic cues may produce unexpected ways of 'being in touch' with a seemingly ordered environment. These cues focus on participants 'noticing' what may be perceived as 'background' or ambient sounds, smells and textures of the built environment. [5]

The design of cues that prompt or invite action in located learning activities is informed by our understanding that sensory interplay is what helps us to interact with our material world. The built environment offers us objects that cannot be 'seen' as a whole from one viewpoint and movement around buildings is therefore important in developing our spatial perception. (Our approach to sensing the city is also informed by alternative approaches to urbanism, ones that heighten perception and counter visual dominance.) As human beings we use 
this sensory interplay to make interpretations of what we experience and learn by collecting, harvesting, sharing, describing, filtering, analysing what we sense. Digital mobile devices now offer integrated tools for collecting, publishing and subscribing to the Web to support networks of human sensors producing data about the live environment. The impact of this can be seen in the networks of data that spring up in response to extreme largescale emergencies and disasters. In their comprehensive overview of the 'overlapping domains' of citizen sensing Boulos et al describe the kinds of map that provides 'situational awareness' of ground level information that is so important in 'crisis management operations'. [6] They describe 'people in the loop' operating as human sensors by gathering and sharing data using their personal mobile devices and in doing so, are both consumers and producers of local information. And in a very different context, artist Cristian Nold has developed biomapping technology using galvanic skin sensors and GPS that enables people to record their emotional responses to their local environments. These responses are collectively published on an emotion map to reveal how they feel about places. [7] We have further explored the concept of situated awareness in Located Lexicon by making two kinds of tool that aim to find out how people feel about place. The first tool uses infrastructural terms from the built environment to search-and-visualise large-scale UGC and the second asks individual users to place a value on, and describe their location in response to a broadcasted query.

Another early pioneer in participatory sensing is the Internet service Pachube now rebranded as Cosm. Pachube was a global and crowdsourced platform for sharing real-time environmental and energy data. As Cosm, its aim is still to facilitate interaction between remote environments, allowing people to monitor and share environmental data from sensors set up by groups and individuals. The greatest effect of grouping can be seen in disparate separated sensor sources coming together into a larger system, one that could compare and challenge authoritative or governmental sensor data in a service where, importantly, the data is accessible to all. This was most visibly witnessed in the aftermath of the Fukishima DaiiChi nuclear disaster in Japan 2011 as individual citizens and agencies attached Geiger counters to Pachube, gathering data that challenged official governmental information on the levels of released radiation. This raises some very important questions about data quality and reliability for participatory sensing. In the Fukishima example, how can anyone be sure that every sensor is calibrated and positioned in the same way? What are the protocols or rules that would constitute a balanced and comparable reading from multiple devices? There is no simple way to standardise disparate users and devices that in broad scientific terms would make for trustworthy data. Usman Haque and Ed Borden counter this argument by stating:

You figure out what convinces YOU yourself. You have agency. Open data increases this engagement. An open data framework, enabling crowdsourced data aggregation, also means a lot more data points, geographically and historically distributed. There's a good argument for saying this is not clean data; but even in official datasets there is a need to clean up outlier points, adjust for dynamic range, etc. What these, usually considerable, extra data points get you is a more detailed picture of trends, a better of idea of what's actually happening in realtime, and maybe even a better picture of things that the official datasets weren't even looking for. [8]

Haque and Borden make two important points. Firstly they say more is better; the more data there is from multiple sources, the easier it is to eliminate exceptional data once averaged. This concurs with the crowd theory assertion that data averaged from multiple sources will give a closer, more accurate answer. [9] Secondly they argue that if somebody operates as a participative sensor they are immediately more engaged and aware of their surroundings. We have tested this theory out in Where's Fenton? by making an app that asks users to 
count and log the number and type of deer they spot in Richmond Park. This project experiments with accuracy and authenticity of data sourced from users of the park who we ask are 'experts' in being able to distinguish between two types of deer, count with some accuracy ('about' is acceptable) and offer further tracking information (eg they are moving off south west towards...)

GeoGraph UK is another example of an Internet citizen participatory project instigated by Gary Rogers in 2005 and adopted by Ordnance Survey to compile a database of images that reflected every kilometre grid square in the UK. [10] The idea is that anyone can contribute images but that the image must be representative of the main 'features' of that location. In effect what GeoGraph does, is set up a protocol system of simple rules to adhere to:

1. Clearly show at close range one of the main geographical features within the square

2. Include a short description relating the image to the map square

3. Photograph a subject in a way that could be useful to a child in interpreting a map

The images are moderated to make sure they meet these criteria by volunteers and if an image is accepted and is also the first image from that particular grid square, the photographer gets a point award linked to their profile showing their value as a user. GeoGraph is an effective illustration of a system with very clearly defined objectives and goals for participants and differing roles and opportunities for user participation. The other vital ingredient in GeoGraph is the reliance on the interpretation skills of the individual - to discriminate by composing an image and text description that captures the essence of a location. In this way, rules or instructions that define the kind of UGC can be seen to work in conjunction with individual creativity - it isn't one or the other.

\section{Sensing technologies and learning}

Current smartphones can serve as communication devices between technological sensors positioned in the environment, as tools with built-in sensors (accelerometer, ambient light, digital compass, gyroscope, GPS, dual microphone, proximity sensor and dual camera) [11] and as sensor-app enabled devices (altimeter, theodolite, geological surveying and so on). This range of functions allows us differentiate between users who explicitly use these devices to collect data and those who 'unknowingly' gather sensor data. Lane et al go further and suggest there is a difference between active and passive participation that can be described in terms of sensing paradigms. Active is described as participatory sensing, and passive as opportunistic sensing. We know that participatory sensing involves learners in actively using, developing and producing data through: collecting, selecting, filtering, problem-solving, leveraging intelligence, utilising common sense and experience, adapting and contextualising. And this raises issues of reliability, mobility patterns, data quality and abundance, and personal goals. Rather than see these as problems for an algorithm to solve, they provide a starting point for understanding participatory sensing as a learning process that actively engages human senses and perception combined with mobile device sensors to collect data from and about the physical environment. And this is what for us encapsulates participatory sensing for mobilised learning. We envisage that as sensor technologies continue to become more user friendly and are better able to 'learn' behaviours, ambient context, types of activity and so on it is even more important to be able to define what motivates mobile learners to participate in gathering data - what's the point for them? 
Yrjö Engeström's 'concept of encounter or boundary encounter' in shared goal-driven learning activity has very much informed our pedagogical framework for participatory sensing. [12] Drawing on Cussins' theory of cognitive trails, he suggests that learning is exploratory movement in space and that meaningful encounters occur between 'heterogeneous actors and their lines of movement' that Engeström likens to knot forming. These collaborative 'knots' are particularly critical between 'predominately non-linear wayfaring trails and predominantly straightforward lines of transport.' Using this analogy, we can continue to explore the question of what makes authentic data in participatory sensing by focusing on the points of intersection between official, stable, centrally produced data and local, temporary, peer-produced data (Figure 1).

\begin{tabular}{|l|r|r|}
\hline Top down data production & Bottom up data production \\
\hline Centrally determined rules & Agreed rules \\
\hline Global knowledge & & Relocalised implementations \\
\hline Given goal & & Mutual goal \\
\hline Loose peer-to-peer networks (more \\
anonymity, low social control and \\
less user involvement)
\end{tabular}

Figure 1: Opportunities for Mobilisation in Participatory Sensing informed by Goodchild. [13]

A good example of an intersection around expertise and scale that provided an opportunity for mobilisation is 9 year old Martha's blog on her school dinners (http://neverseconds.blogspot.co.uk/). Tasting and recording the content of her school dinners using a camera, Martha expertly described the content of each meal and gave it her own personal scores - including food-o-meter, number of mouthfuls, pieces of hair and health ratings. The blog went viral when the local council temporarily banned her from taking photos and followers on Twitter retweeted support for Martha's blog. The ban was subsequently removed and Martha continued to take photos of her school dinners and share data sent in by others around the world. 
Following on from Haque and Borden's suggestion that participatory sensing can provide a better picture that 'official datasets weren't even looking for', we can argue that instigating an enquiry, or 'what to sense', may be prompted by looking for what's not there in the datasphere and taking action. Furthermore, Martha's self-selected task works together with her individual identity communicated through her blog to generate a high level of, what Michael Bauwens would call, 'value affinity' in peer-to-peer networks. [14] Bauwens describes the challenge of these networks is to create real social communities and localised implementations. In suggesting that ' $[\ldots]$ one needs to strive for a correct balance between agreed-upon frameworks, that are community and consensus-driven, and the need for individual creativity and dissent' he also highlights a need for networks to be diverse and inclusive to generate positive behaviour rather than replicate existing hierarchies. This is not as simple as 'swarming is good' but acknowledging that a top-down, one-way information flow is being challenged by people acting 'horizontally' in groups. ${ }^{1}$ In our project, Tall Buildings, we have created a core service that creates different levels of challenge in using the height of buildings to navigate a path through the city (such as working in a group, setting constraints and so on). This has opened up our thinking on why people take action, from literally getting out of their chair and going for a walk to making and publishing data about their experience; people may be mobilised passively and/or actively into being citizen sensors and we differentiate between these as modes of learning. We understand that learners operate interchangeably between different roles as users and that these attributes inform and develop creativity.

We are interested in designing projects that have built-in opportunities for people to be mobilised into learning - by themselves and/or with others. Official sources of data provide centralised information that can be utilised (with or against) that produced horizontally or locally and that this opens up discussion on what we mean by expertise. And so our pedagogy for location-based learning places the live physical environment at the heart of what mobilises people into taking action and we seek alternative ways of sensing this - or making the seemingly invisible, visible.

\section{Motivating participation: 3 projects}

In our early research into Web services that use geo-locative features to enable production of UGC on the move, namely Twitter and Flickr, we noticed two fundamental problems. Firstly users were reticent to use locative media because of fears about the possible implications of their location being known and secondly, location wasn't of primary importance when people used these services. The thought of anybody on the Web knowing your identity and physical location at any one time is extremely worrying for most of us. It feels like a very clear line has been blurred or broken between our online presence and our physical selves. In the media this risk has been framed in the context of criminality - the fear of stalking and burglary, risks to family members

\footnotetext{
${ }^{1}$ Boulos et al have produced a set of points that help to clarify important elements of horizontally shared data and requirements of technologies that we have found useful in designing opportunities for mobilised learning into projects, especially when considering issues of anonymity and authenticity. http://www.ij-healthgeographics.com/content/10/1/67 Accessed 12 June 2012
} 
especially children - but more generally it is that creeping feeling of an invasion of privacy, people knowing what you are doing, where you go and what you like to do when you're there.

This fear has been exacerbated by a lack of understanding about what kind of location data is attached to the things we share on the Web. Many of us don't know what we have agreed to share with a service; we are unaware what extra bits of metadata are stored and when we realise that location data is recorded we are uneasy. This was clearly illustrated in 2011 when two UK based researchers Pete Warden and Allisdair Allan announced that iPhone devices were recording location in a data file without the explicit knowledge of the user, even though in the 'end user licensing agreement' EULA Apple make clear that it may collect such data (http://www.geekosystem.com/iphone-tracking/). Research supports what most of us know - we don't read those agreements and when we find out a service is doing something unexpected we are surprised and concerned about their motivation. This unease and insecurity has led to location-based services being shunned by many of us, especially in services where location has been introduced after users have joined that service.

Twitter introduced location-based services at the end of 2009 allowing tweets to be tagged with latitude and longitude if the user explicitly turned on the service. Previously the location of a tweet was the address the user manually entered when joining the service, often just a general place name such as 'London'. This new 'geolocation' feature is only really relevant for users on the move with GPS enabled mobile devices. In 2011 Twitter CEO Dick Costolo was quoted saying that $40 \%$ of tweets were from mobile devices, but research from Texas A\&M University [15] has suggested that only $0.42 \%$ of tweets had active geo-location data attached. This low take up is possibly because there is no real incentive to have location switched on especially when weighed against the perceived risks.

We have explored these issues in our project, Located Lexicon, in which we were interested in the words or metadata that people write about a location and how these might be linked to other words to form a lexicon of terms. [16] We produced a tool that allowed us to search-and-visualise crowd sourced data posted via social media platforms in a specific location. The tool required geo-location to be switched on but no 'sign up' identity in order to suck up tweets or metadata posted on Twitter or Flickr in a location over a period of time using a specific set of search terms (two or more words) to filter and then visualise the results. In our experiments the tool was used to trawl for word matches and produce a map that showed where they were posted. The identity of the contributors was not important, but rather the words (or metadata) they were using to describe where they were and that they had switched geo-location on. In our study of geo-located tweets scraped from Trafalgar Square in London over a sunny weekend we found that the subject matter of the vast proportion of tweets bore no relationship to their location whatsoever, they could have been written anywhere. However when we looked at tweets that had a link to a photo, we made an interesting observation that more often than not the tweet contained text relevant to the location. It seemed that by adding a photo, location became relevant. Our research for this project included an experiment to see whether we could visualise users' location temporally. We scraped up geo-located tweets using the term 'sunset' over a set period of time and then drew a vertical line on the horizontal longitudinal position of the tweet on a world map, with the colour of the line defined as the time of day (Figure 2). You can clearly see the colour change as the term 'sunset' is 
tweeted from around the world at the time the sunset is happening. This is very basic global participatory sensing at work, users aren't actively contributing, but their tweets clearly are associated with their location and it clearly shows people have sensed and communicated about the locality they are in at that moment.

Located Lexicon explored 'situated awareness' through using a tool to suck up and plot data from a mass of UCG and produced interesting maps that showed densities and distribution of geo located data (Figure 3). Tweeters were unaware that their data had been used in unintended ways and therefore unsurprisingly, there was a mismatch between the content of the data and the purpose of our enquiry. What we can take from this is that location has to be integral to how the service is perceived to be used - for location to 'work' it has to have a relevancy to the data it is linked to.

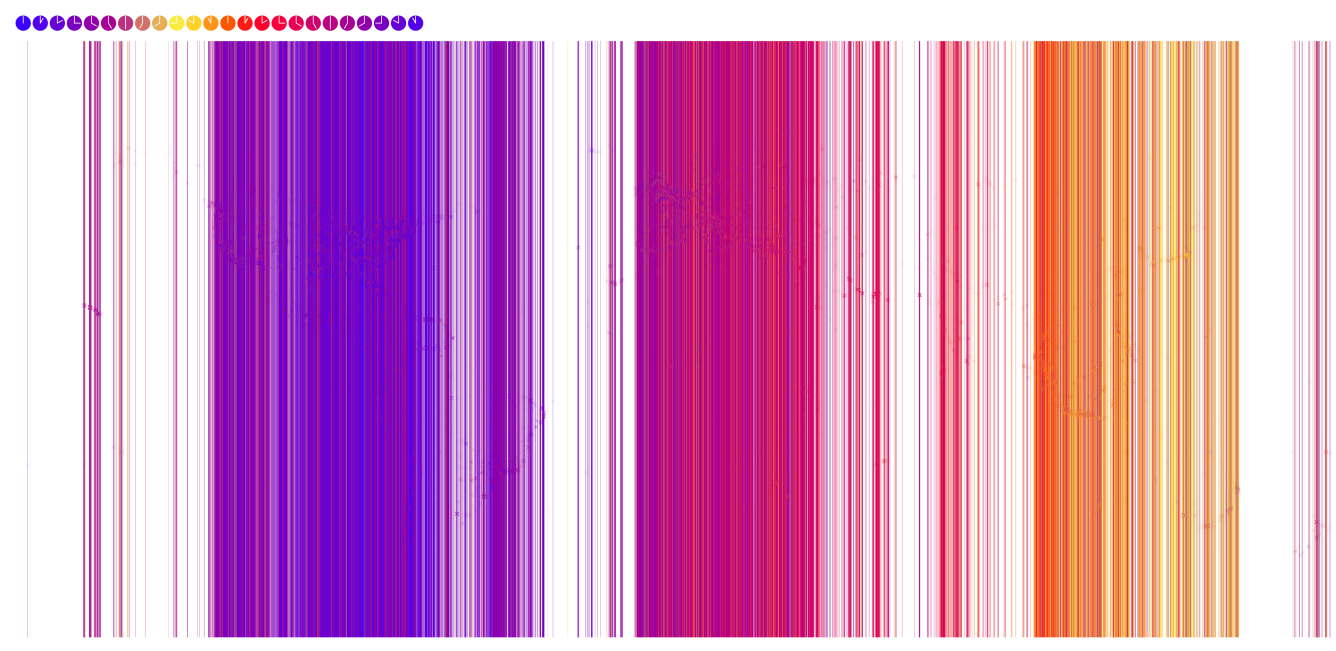

Figure 2: Located Lexicon - Visualisation of Sunset Tweets, August 2011.

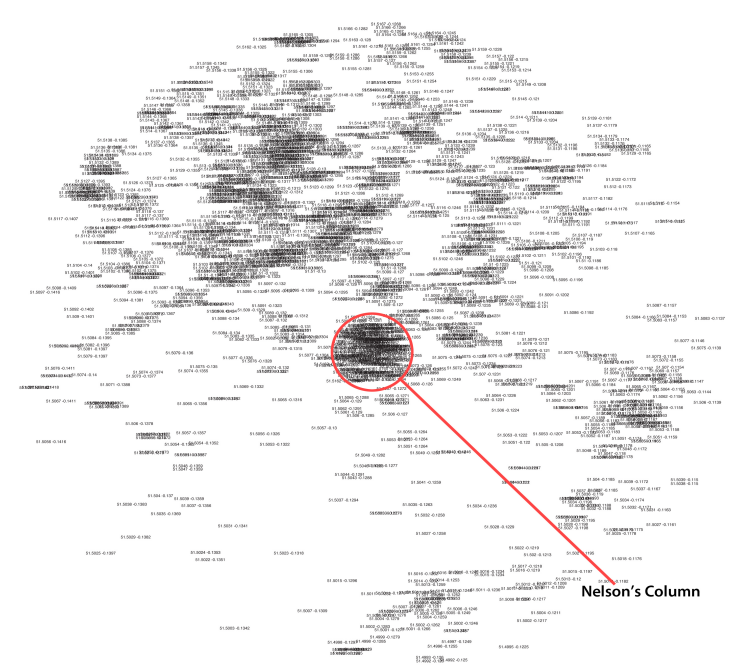

Figure 3: Located Lexicon - Visualisation of Tweets Posted With 100m of Nelson's Column, July 2011.

If the identity-and-location connection is perceived as a barrier to participatory sensing one obvious solution would be to break the link between individual identity and the locative data transmitted, in other words making 
the data anonymous. Identity is an integral part of so much UGC on the web, especially social media services like Twitter, blogging and even services that directly gather sensor data such as Pachube. We wanted to see what a service would be like if used anonymously to input sensor data that could be shared and used by others. We created a prototype application called Where's Fenton? - a service that tracks the location and number of deer in Richmond Park, London. In the app there is a shared map where anyone can upload 'spots' to the database of the location when they see a deer or group of deer. We made the app public via the Apple App Store and asked some test users to give it a go.
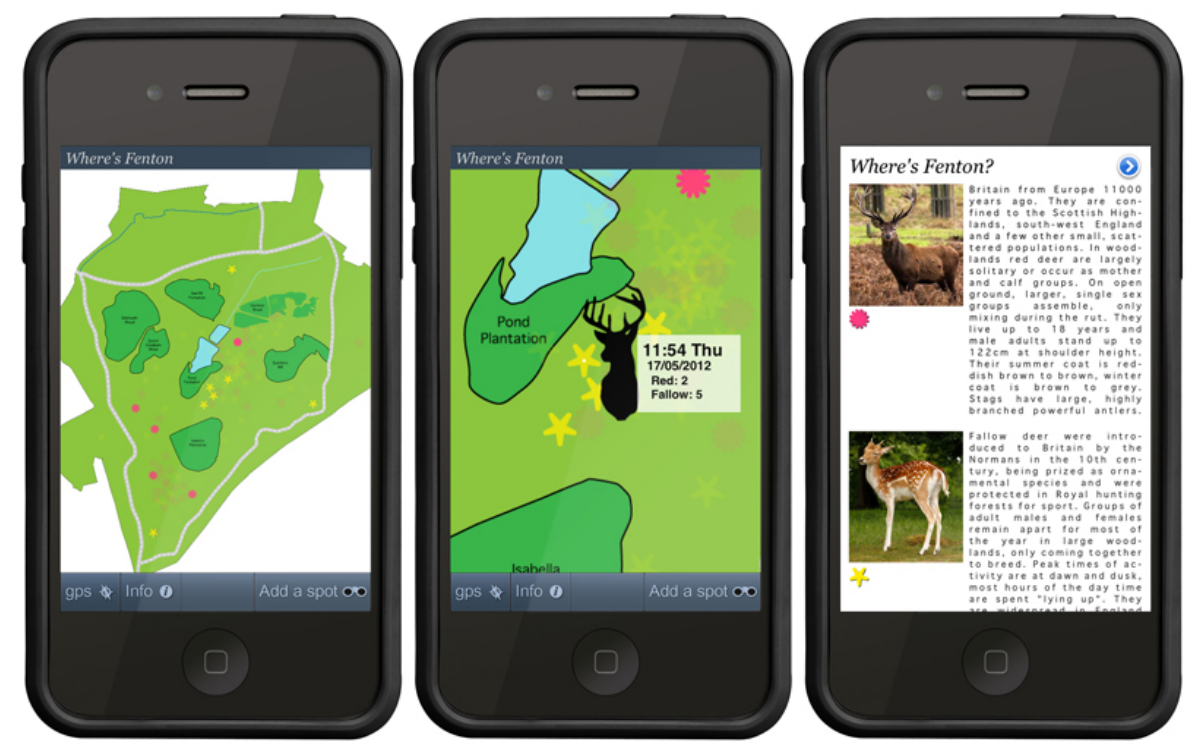

Figure 4: 'Where's Fenton?' iPhone app interface, 2011.

We learned a lot from the test users about how identity or lack of it affected their use of the service and several trends started to emerge that have also been identified in other participatory sensing projects. One user found that they wanted to know which spots were theirs over time, another conversely wanted to know which user put which spot because some spots seemed to be more accurate than others. Another user was worried that the service was open to abuse, because they could easily see how to abuse it themselves. Crowd sourcing research tells us that users of a service are more likely to contribute and publish when they can be acknowledged, they also tend to behave better when they are known and when that reputation has an effect in other areas of their life. Identity also helps us to make assumptions about quality; if you have various answers to a question how do you choose the correct one? It makes sense that you would trust the answer from a verifiable expert more than from someone you knew nothing about. Identity of the source helps validation and encourages confidence in the information shared.

From the world of crowd sourcing, the term 'halfnimity' is useful in exploring these issues of user motivation, behaviour and contributions in participatory projects. [17] A halfnimous service is one where people adopt a fake user name that is tied to your real name. Robertson gives an example of taking the first letter of your first name putting it with your surname (Pete Rogers would be progers). With this name it is hard for someone who doesn't know Pete to identify him, but for someone who knows his name and is perhaps aware that he uses that 
particular service would predict that it could well be him. Robertson describes it as a "non-linear curve in transparency. If someone does know you, it's as good as non-anonymous. If they don't, it's as good as anonymous.' We like this description and way of handling user details so that you can keep the benefits of reputation building if that is important to your motivation to engage in using a service and another user can still trace whether any particular individual is giving 'bad' information that you might choose to ignore. We can begin to see how halfnimity is not only relevant to the opportunities for mobilisation presented in Figure 1, but also in providing a service that directs people to learn something new about their environment by offering them different modes of engagement in a located and focused activity. And we now explore this further in our most recent project, Tall Buildings.

Is it possible to combine the different approaches to contemporary urbanism with a "sensorial urbanism," capable of offering a broader understanding of urban settings, interested in describing the character and atmosphere of places, and aiming to contribute to a new definition of public space? [18]

In this project we were interested in alternative ways of viewing and navigating the city. The city being London for us, but any major city would do. We wanted to see if we could develop tools that enabled people to sense the urban landscape by engaging in a focused activity. To do this we used dimensions of distance and altitude to develop a service that is based on finding, accessing and recording the height of vantage points in the urban landscape. The idea of a populated panorama as a detailed view of the city is both an historic and contemporary one. The earliest detailed topographical depiction of London is cited as Anthonis van den Wyngaerde's Panorama of London 1539-44. ${ }^{2}$ These drawings use the Thames as the main feature to locate buildings, bridges and spires of the city in the mid $16^{\text {th }}$ Century from vantage points along its banks.

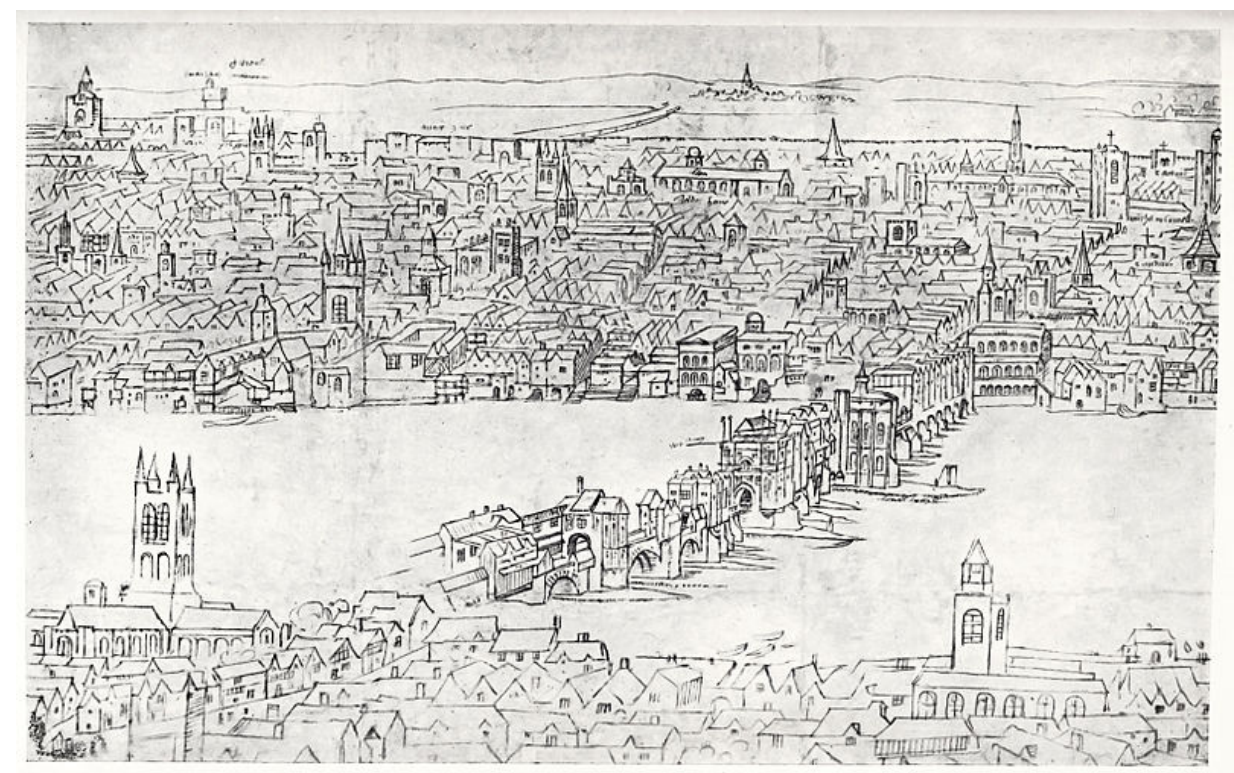

Figure 5: Drawing by Antony van de Wyngaerde, London Bridge ${ }^{3}$

\footnotetext{
${ }^{2}$ Royal River: Power, Pageantry and the Thames exhibition at the National Maritime Museum, London. April-September 2012

${ }^{3}$ Drawing by Antony van de Wyngaerde, London Bridge (one of 7 drawings that make up the Panorama of London, c. 1554-57). http://en.wikipedia.org/wiki/File:Wyngaerde London - London Bridge.jpg Accessed June 2012
} 
Vantage points today are used professionally in urban and landscape planning, archaeology and the military to survey areas of land that are in the line of sight (commonly known as 'viewsheds'). Our focus, however, was in everyday public use of vantage points to gain different perspectives and views. As on previous projects, we operated a live walk research method to sound out the potential of vantage points as a way of developing this kind of situational awareness. We set an enquiry for the walk that involved finding something that we thought might be hidden. Being interested in decaying, 'at risk' buildings that are difficult to access, especially those at with social histories, we got to know about the campaign to save the former Strand Union workhouse in central London. We wanted to find out if we could see this building in its primary context. The walk highlighted how buildings could be accessed and used as vantage points to view objects of interest and in the guise of an adventurer, what it felt to experience the thrill of a new perspective gained in unexpected ways. How could we develop this kind of opportunity for learning into the design of a service that mobilised others into finding vantage points but didn't prescribe their experience?

Our brief for Tall Buildings was to create a system or game where we could see from one vantage point to another and step in between to the next point and then go beyond. In other words, could we make a game where you stand atop or near the top of one publicly accessible structure and identify the next roof or near top and navigate to that point. We wanted to see if we could create a user generated map that showed the publicly accessible tall structures in a town or city so that people could playfully move from one structure to another and see how far they got. How concentrated and close together could this web of vantage points become? Our project would provide a focused activity for pedestrian sensors to learn on the move by:

- Sighting emblematic buildings, monuments and structures (eg Nelson's Column) from various vantage points

- Working out a route or path from one vantage point to another

- Mapping altitude, time and distance data for each vantage point

The service we have made invites people to engage in four distinct but interchangeable modes of learning - as developers, adventurers, mashers and tourers. Developers are like us, people who take an idea or concept and work it through into a practical outcome. We primarily operate in this mode by developing a core service that invites others to learn through using it. Adventurers are insider experts who exploit the core service to the full, interactively using what we provide to make, share and publish their own data. Mashers are those who take our service and feed off it to pursue their own interests and needs; they build on the service, develop and use it in unintended ways. They may for example combine altitude data of tall buildings from our service with geological data below from elsewhere to visualise vertical strata of above and below a city skyline. Tourers tend to use the service as given, as voyeurs who enjoy the experience the service offers them. What is important about these different kinds of user is that they are interchangeable. A tourer may dip into being an adventurer, a developer into a masher, a masher into a developer and so on but in making these explicit means that we are inviting people to learn in different ways. 
The core service for this project is a map on that visualises the height of buildings and distance travelled between them. The intended use of this service involves users in finding and climbing up tall buildings or structures, entering their height data and a photo of the view. They use the view from the building or structure to work out where to go next. Users are able to see all of the high points they have climbed on their journey on the map as a series of extruded points. These points are like the teeth of a saw; the taller the teeth and the closer they are together, the better. The map can be added to over time or done as a one-off activity. It gives you a record of buildings climbed and the views from them. It's not just about finding buildings but getting into them. Issues around what constitutes public space at ground level and higher up, who you talk to get into a building, awareness of surveillance and costs attached to roof top locations are all part of the experience. As with other physically located activities the level of challenge is important in determining the kind of learning experience.

(Figure 6)

\begin{tabular}{|c|c|c|}
\hline \multicolumn{3}{|c|}{ Pick-n-mix factors affecting the challenge of a Vertical Excursion } \\
\hline \multicolumn{2}{|c|}{ Easy } & Challenging \\
\hline Access & $\begin{array}{l}\text { Entry is welcomed } \\
\text { There are lots of public areas } \\
\text { You are free to roam }\end{array}$ & $\begin{array}{l}\text { Have to con/blag your way in } \\
\text { There are lots of private areas } \\
\text { You are expected to follow set rules }\end{array}$ \\
\hline Cost & Free or within budget & Low or no budget \\
\hline Distance covered & $\begin{array}{l}\text { Higher the building the bigger the area for spotting } \\
\text { next vantage point } \\
\text { More stretched topographical profile }\end{array}$ & $\begin{array}{l}\text { The lower the building the smaller the area for } \\
\text { spotting next vantage point } \\
\text { More squeezed topographical profile }\end{array}$ \\
\hline Density of buildings & $\begin{array}{l}\text { Low number of vantage points climbed } \\
\text { Occasional vantage point to head for }\end{array}$ & $\begin{array}{l}\text { High number of vantage points climbed } \\
\text { Multiple vantage points identified }\end{array}$ \\
\hline Location & $\begin{array}{l}\text { High number of publicly accessible } \\
\text { buildings/structures } \\
\text { Good local knowledge of (or unlimited access to } \\
\text { experts/reliable information) accessible tall } \\
\text { buildings/structures }\end{array}$ & $\begin{array}{l}\text { Low number of publicly accessible } \\
\text { buildings/structures } \\
\text { Poor local knowledge of (or limited access to } \\
\text { experts/reliable information) accessible tall } \\
\text { buildings/structures }\end{array}$ \\
\hline Height of vantage points & $\begin{array}{l}\text { No constraints } \\
\text { Use mobile technologies to calculate } \\
\text { building/structure height (eg theodolite app) }\end{array}$ & $\begin{array}{l}\text { Constraints set - eg max/min height range, most } \\
\text { undulating/straight topographical profile } \\
\text { Work out height of buildings/structures 'by hand' }\end{array}$ \\
\hline Navigation & $\begin{array}{l}\text { Use GPS-enabled map to find your way to the next } \\
\text { vantage point } \\
\text { No constraints on method of travel }\end{array}$ & $\begin{array}{l}\text { Use your vantage point views to predict a route } \\
\text { onwards by spotting thoroughfares, railway lines, } \\
\text { landmarks etc. } \\
\text { Constraints on methods of travel }\end{array}$ \\
\hline
\end{tabular}

Figure 6: Core service factors affecting level of challenge. 
Creating applications that use geo-location services inevitably involves designing for mobile devices. Development for multiple systems can incredibly cumbersome especially with many different platforms and hardware that change with great frequency. Through our process we have found that a design structure that splits client side development (the mobile app) from the data source (the web database) with a clear open link between them works best. Our solution for the development of Tall Buildings was to create a scalable web database and robust application programming interface (API) allowing any client application to interrogate and augment data on that database. In other words we wanted to create a 'handshake' between the data on the server so that a client written by us and by third parties could communicate with the central store of data. This paradigm fits neatly with the types of user we want to encourage - especially enabling the masher to create their own client side application that interrogates the tall building data in new and unexpected ways, perhaps even combining the tall building data with another service or dataset to create a new type of activity. Allowing the data to be grabbed and manipulated through our public API allows for multiple platforms and clients to be designed allowing adventurers different types of tools to gather and share their data on multiple systems. For example, our system allows adventurers to add locations via Twitter through a simple web interface. All of this benefits the tourer who would have a myriad of tools at their disposal to access the data, through mobile clients, web apps and third party sources such as Twitter, Flickr or Foursquare.

In Tall Buildings we wanted to encourage an activity but not prescribe one; users are free to participate in collecting data, but we also wanted users to be able to just use the data for their own means (for example as a simple map of accessible tall buildings, so they could pick one close to them to share a sunset with somebody). The user activity that we encouraged would be directly related to the data gathered. So we came up with the concept of a shared 'saw tooth' graph. (Figure 7)

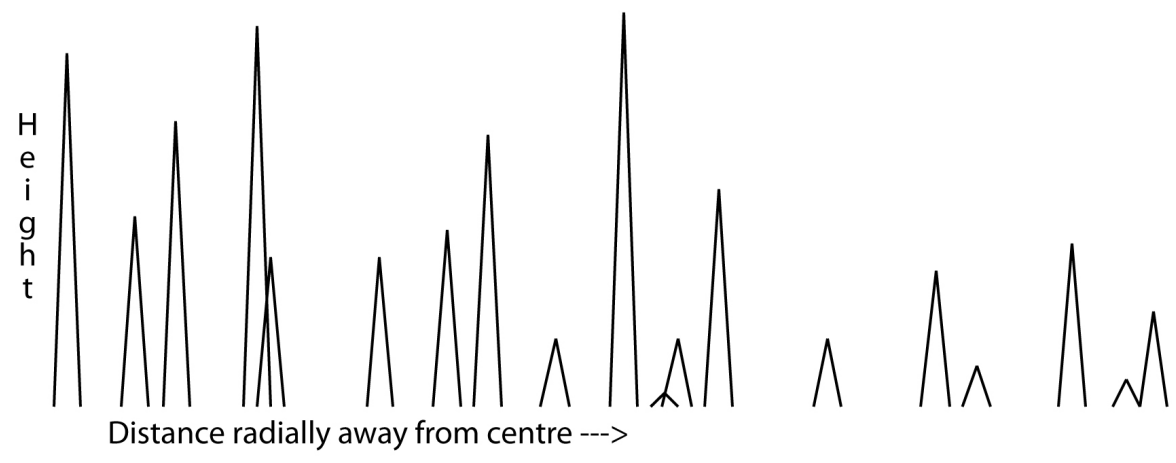

Figure 7: Tall Buildings - ‘Saw Tooth’ Graph.

This graph visualises the base assets of the data - the height and distance between points. We placed value on proximity and height; the higher the location and the closer each location is together, the better. This is visualised as a 'tooth' on a 'saw' for each individual location. The graph is produced from data gathered by the individual user and also as a shared graph of all users to enable locations to compete for the most accessible tall buildings shown through the growing number of points on the 'saw tooth'. The saw tooth graph acts as an illustrative tool to show the density of user input and the corresponding quality - in this case, height. It also 
gamifies the activity, encouraging an adventurous user or group of users or city space to fill in the gaps by drawing the teeth of the graph closer together.

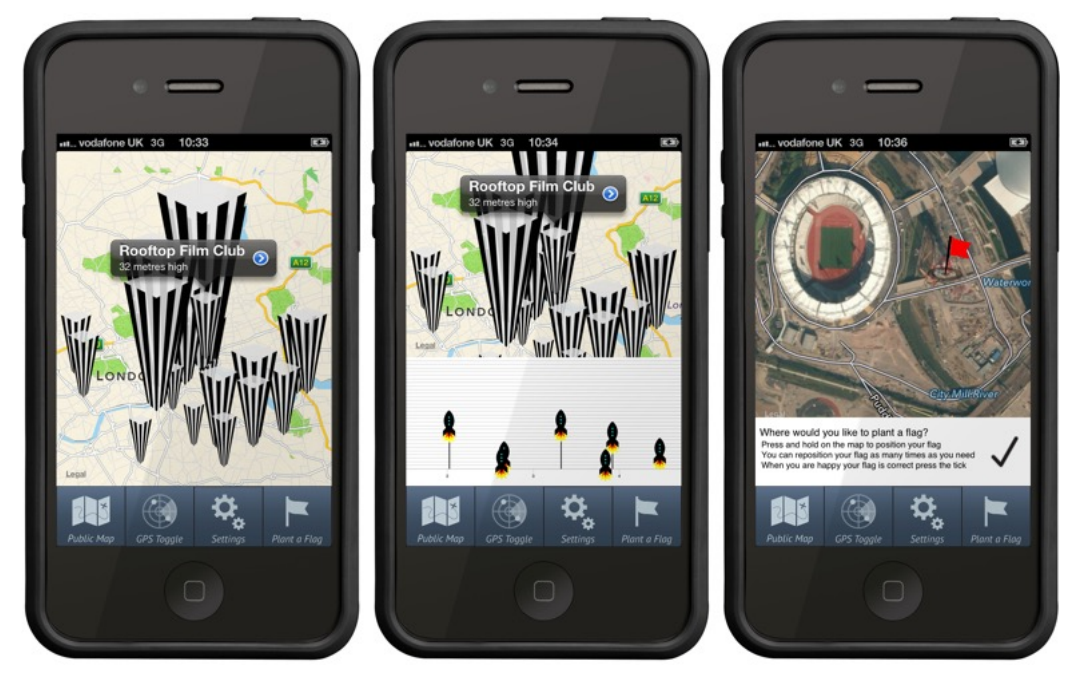

Figure 8: Tall Buildings - iPhone app interface, 2012.

The Tall Buildings app (Figure 8) works by users planting a flag for a tall building on the map. The flag acts as a location marker but also provides information on the name of the building or structure and how to access it. Users are asked to write a 'location name', then answer 'how did you get in?' followed by 'enter the height in metres' before checking all is correct and planting their flag. The public map then represents the flag as an extruded building and also as a rocket ('tooth') on a height-distance graph. By clicking on the extruded building, users can access this metadata via a tag and toggle GPS to find out the nearest tall buildings in their current location. And the settings function allows them to switch between two kinds of map view (roads and buildings or satellite view) as well as the choice to add an identity if they want to 'show off how many places you've explored'.

The app has been designed to facilitate the four interchangeable types of user we identified in the development of this service and we are now engaging in a series of trials to see how the prototype app works as a participatory sensing tool. In operating primarily as developers on this project so far, we are now ready to test what we have made in ways that invite different kinds of interaction and therefore, learning experiences. We know that buildings have codes of behaviour in how people use them so we are excited to find out if the Tall Buildings app contributes to alternative ways of sensing the city.

\section{In conclusion}

User evolvement of a core service has been the cornerstone of our research practice since playing as mudlarks in 2005. Our understanding of evolvement has moved from creating initial content around a subject of interest that is designed in such a way as to prompt users to add to this in location, to creating services that can be utilised as tools for learning through users engaging in defined interchangeable roles. Developments in crowd-sourced data have involved us in exploring how user generated content can be scraped up, filtered and re-presented for 
further analysis. In this we have always been conscious of the need to present data through interactive maps and tools in ways that invite questions and further opportunities for learning. This journey has come to a point where we believe that a focused enquiry, event or project is important in generating meaningful located learning experiences that engage service users in developing situational awareness.

We have found that participatory sensing works best when it has a clear goal (as in GeoGraph) that can be explained in the simplest terms and is supported by tools that work well to achieve this goal. This has often involved us in stripping down lots of ideas and possibilities in developing a project so we can answer the question - why is this work important? If we can define this for ourselves, then we are more likely to be able to communicate this to the user. We have also found that when a user really participates, it is the activity of discovery that propels them to do so; our tools and applications have to encourage active participants rather than passive interpreters. Our projects have also indicated that for a service to thrive there needs to be many users and data points, and to do this they need to feel reassured that the data they gather is not going to be used in a way that is unexpected or insecure.

On a service level we found it important to separate the client or device design and the server or data store. And that for a service to truly work, you must encourage unexpected augmentation of your data, including encouraging alternate ways of collecting data and visualising the results. We have realised that tools given to a user and/or the types of data captured will effectively prescribe how a user perceives using that service and, often in quite unexpected ways, will determine their activity. Our research has highlighted that metadata or associative data can be of more relevance to describing location especially when mixed or augmented with other data sources.

Working out how best to create services that involve citizens in describing the granularity of location has been underpinned by an interdisciplinary pedagogical investigation. By drawing on theoretical concepts of 'knots' and 'networks' we have opened up thinking around what is means to be a mobilised pedestrian sensor and how this might be developed to invite participation in a located project or event that answers every learner's question, 'What's the point for me?' 


\section{References}

[1] Boulos M (2005) Web GIS in practice III: creating a simple interactive map of England's Strategic Health Authorities using Google Maps API, Google Earth KML, and MSN Virtual Earth Map Control. International Journal of Health Geographics 4:22. doi:10.1186/1476-072X-4-22

[2] Sprake J (2012) Learning-through-Touring: Mobilising Learners and Touring Technologies to Creatively Explore the Built Environment. Sense Publishers, Rotterdam/Boston/Taipei: 149-183

[3] Sprake, 2012: 25

[4] Rodaway P (1994) Sensuous Geographies: Body, Sense and Place. Routledge, London

[5] Sprake, (2012): 150

[6] Boulos M, Resch B, Crowley D.N, Breslin J.G, Sohn G, Burtner R, Pike W.A, Jezierski E and Chuang K.S (2011) Crowdsourcing, citizen sensing and sensor web technologies for public and environmental health surveillance and crisis management: trends, OGC standards and application examples. International Journal of Health Geographics 10:67. doi:10.1186/1476-072X-10-67

[7] Nold C (Ed) (2009) Emotional Cartography: Technologies of the Self. http://emotionalcartography.net/ Accessed 8 June 2012

[8] Haque U and Borden E (2011) Volume \#28: Internet of Things. http://volumeproject.org/blog/2011/11/16/data-and-owner/ Accessed 14 July 2012

[9] Surowiecki J (2004) The Wisdom of Crowds. Little Brown, London

[10] http://www.geograph.org.uk/ Accessed August 2012

[11] Lane N.D, Miluzzo E, Hong L, Peebles D, Choudhury T, Campbell A.T (2010) A Survey of Mobile Phone Sensing. IEEE Communications Magazine 48:9

[12] Engeström Y (2009) Wildfire Activities: New Patterns of Mobility and Learning. International Journal of Mobile and Blended Learning 1.2: 1-18

[13] Goodchild M.F (2007) Citizens as sensors: the world of volunteered geography. GeoJournal 69: 211-221

[14] Bird L (2010) An interview with Michel Bauwens founder of Foundation for P2P Alternatives. Furtherafield.

http://www.furtherfield.org/interviews/interview-michel-bauwens-founder-foundation-p2palternatives Accessed 12 June 2012

[15] Cheng Z, Caverlee J, Lee K (2010) You are Where you Tweet: A content based approach to geo-locating twitter users. 19th ACM International Conference on Information and Knowledge Management. ACM 978-14503-0099-5/10/10

[16] Sprake J and Rogers P (2011) Located Lexicon: a project that explores how user generated content describes place in Sonvilla-Weiss S \& Kelly O (eds.) Future Learning Spaces: Designs on eLearning Proceedings. Helsinki, Aalto University Publications: 219-234

[17] Robertson N (2010) Halfnimity. The Trada Blog. http://www.trada.com/blog/anonymity-incrowdsourcing/ Accessed August 2012

[18] Zardini M (Ed) (2006) Sense of the City. Lars Muller Publishers, Quebec: 24-25 